\title{
Eating Habits Among Medical Students at King Abdulaziz University, Jeddah, Saudi Arabia
}

This article was published in the following Dove Press journal:

International Journal of General Medicine

\author{
Sami H Alzahrani (D) \\ Abdulmajeed Abdulaziz Saeedi ${ }^{2}$ \\ Maan Khaleed Baamer ${ }^{2}$ \\ Abdullah Faisal Shalabi ${ }^{2}$ \\ Abdullah M Alzahrani $\mathbb{D}^{3}$ \\ 'Family Medicine Department, Faculty of \\ Medicine, King Abdulaziz University, \\ Jeddah, Saudi Arabia; ${ }^{2}$ Faculty of \\ Medicine, King Abdulaziz University, \\ Jeddah, Saudi Arabia; ${ }^{3}$ Family Medicine \\ Department, King Saud bin Abdulaziz \\ University for Health Sciences, King \\ Abdulaziz Medical City, Jeddah, Saudi \\ Arabia
}

Background: Eating habits are a major concern with regard to the health status of university students. This study aimed to identify patterns of eating habits among undergraduate medical students and to investigate their relationship to sociodemographic, socioeconomic, and psychological factors.

Methods: This cross-sectional study included 378 undergraduate medical students aged 19-26 from the Faculty of Medicine at King Abdulaziz University, Jeddah, Saudi Arabia. Students were in their second through sixth academic year. Data were gathered with a selfadministered questionnaire encompassing questions on sociodemographics, eating habits, and psychological factors.

Results: Eating habits score was much lower among students who were smokers, lived in rented places, lived alone, had separated parents, and did not exercise regularly. In multivariate analysis, multiple psychological factors, such as living alone and stressed, were found to be associated with eating patterns.

Conclusion: A majority of undergraduate medical students had unhealthy eating patterns, and socioeconomic and psychological elements were significantly affecting eating patterns.

Keywords: nutrition, survey, dietary habits, psychological factors, sociodemographic factors

\section{Introduction}

Healthy eating is one of the most substantial means of enhancing health. A healthy diet includes a balance of natural and fresh foods, a lot of fruits and vegetables, and foods containing minerals and vitamins. ${ }^{1}$ It also involves behaviors and eating habits that are consistent, which is beneficial for supporting and maintaining both physical and psychological health. ${ }^{2}$ Healthy eating is affected by various individual and collective (social and environmental) factors. ${ }^{3}$ In Saudi Arabia, eating patterns have altered considerably during the past few decades because of a fast-rising socioeconomic status at government and population levels. These marked lifestyle changes have affected different age groups, especially children and youth. ${ }^{4}$ Previous studies showed high levels of consumption of refined foods and animal products as compared to fruits and vegetables among Saudi populations. ${ }^{5,6}$

Adult students transitioning from schools to universities experience difficulties adhering to healthy eating habits due to lack of time and stressors, and instead, they skip meals, eat unhealthy snacks, dine out, and consume fast food. ${ }^{7}$ There is a deficit of knowledge about healthy diet options that might passively influence eating patterns and nutrition. ${ }^{8}$ Medical students are expected to possess good eating patterns and have a healthy lifestyle because they have more medical knowledge
Correspondence: Sami H Alzahrani Family Medicine Department, Faculty of Medicine, King Abdulaziz University, P.O. Box 4828, Jeddah 22431, Saudi Arabia Tel +9669500004062

Fax +966I26408403

Email drsamihz@gmail.com 
regarding healthy eating patterns. As such, they are expected to act as role models for their peers in terms of the application of healthy eating patterns. A study in China showed that medical students had risk factors for chronic diseases due to bad eating patterns. ${ }^{9}$ Although medical students possess enough knowledge about healthy dietary patterns, they appear incapable of putting this knowledge into practice. ${ }^{10}$ The stress of university life and medical studies negatively affects their dietary patterns. ${ }^{11}$ Medical education is considered the most academically and emotionally demanding training program. The time and emotional commitments medical students must devote to their training are extensive, and such stress has a negative impact on students' psychological health. ${ }^{12}$ Healthy dietary habits among medical students are important because they are the future physicians, and students who personally ignore adopting a healthy lifestyle are more likely to fail to establish health-promoting opportunities for their patients. $^{9}$

There is a paucity of studies that focus on the effects of psychological factors on eating patterns among medical undergraduate students in Saudi Arabia. Therefore, this study aimed to assess eating patterns and the risk factors for poor eating habits, with a focus on the demographic, socioeconomic, and psychological factors among medical students at King Abdulaziz University (KAU), Jeddah, Saudi Arabia.

\section{Subjects and Methods \\ Study Setting and Population}

This questionnaire-based cross-sectional study was carried out between January and March of 2019 and included 378 undergraduate medical students in any of the second to sixth years of study at the Faculty of Medicine, KAU, Jeddah, Saudi Arabia. The strategy adopted for this study was a double sampling for stratification technique. After arrangements were made with the medical college administration of KAU, students in each of the academic years were randomly approached by phone. Students were excluded if they were pregnant or athletes. After potential participants agreed to participate in this study, the aims and advantages of the research were described to them verbally and they were given a guarantee that the information gained would be confidential and would have no affect on their course progress. The biomedical ethics committee for human research at KAU, Jeddah, Saudi Arabia, approved this study (257-140).

\section{Sample Size}

The participants were randomly selected from students of the Faculty of Medicine, KAU. During the study period, there were 2410 medical students comprising 1184 males and 1226 females in the preclinical and clinical phases of the curriculum, including the second year $(n=609 ; 278$ males and 331 females), third year $(n=491 ; 244$ males and 247 females), fourth year $(n=507 ; 257$ males and 250 females $)$, fifth year $(n=424 ; 217$ males and 207 females), and sixth year $(n=379 ; 188$ males and 191 females). The Raosoft software package (Raosoft, Inc., Seattle, WA) was used for sample size calculation, with the single proportion method. When assuming that $50 \%$ of medical students will have sufficient knowledge of and a positive attitude toward the questionnaire, the required sample size was 380 students at a 95\% confidence interval and a $5 \%$ margin of error. The proportional allocation of the students was performed using a stratified sampling technique as follows: $25.1 \%$ were students in the second year, $18.5 \%$ in the third year, $16.7 \%$ in the fourth year, $21.2 \%$ in the fifth year, and $18.5 \%$ in the sixth year. The total number of students completing the study was 378 because 22 students did not complete the questionnaire.

\section{Study Instruments}

The instrument used was an adapted English-language questionnaire used in previous studies. ${ }^{13,14}$ The questionnaire's reliability was assessed, and the Cronbach's alpha was 0.715 . There were three sections in the survey, where the first section consisted of questions about demographic information such as age, gender, nationality, academic year, marital status, residence, living arrangement, monthly household income, chronic illnesses, medications being taken, education level of parents, whether the parents were separated, if the mother worked, and other questions regarding the student's lifestyle, such as those about exercise and smoking habits. The second section consisted of 12 questions dealing with eating and drinking patterns and types of meals (12 items). For example, the questionnaire probed habits related to regular meals; daily breakfast; meals with or without snacks in between; the frequency of meals; snacks, vegetables, fruits, and fried food consumption; daily water intake; eating with friends and family; consuming fast food; consuming food with balanced nutrition; and type of foods most frequently eaten. The third section consisted of six questions about psychological items that could affect the eating patterns of students. Questions were 
chosen from the validated compulsive eating scale (CES), ${ }^{15}$ which was used to assess uncontrolled eating habits among the college students, exploring factors like eating due to feelings of being lonely, upset or nervous, bored or happy, and completely out of control regarding food, along with eating so much until getting a stomachache. The answers to these questions were "never," "often," or "sometimes." This questionnaire was developed to be administered online.

\section{Statistical Analysis}

The Statistical Package for Social Science version 21 (SPSS Inc. Chicago, IL) was used to analyze the data for this study. Data were expressed as numbers (\%) for categorized variables or mean $+/-$ standard error of mean (minimum-maximum) for continuous variables. Eating habit scores were calculated based on 12 questions, where healthy habits were given a score of 1 and nonhealthy habits were given a score of 0 . Therefore, the maximum possible score was 12 . The score of eating habits was compared between different demographic groups, groups of social factors, and psychological factor grouping using the unpaired Student's $t$-test between two groups and one-way ANOVA (least significant difference) between more than two groups. The significance level was set at $P$-value $\leq 0.05$.

\section{Results}

\section{Socioeconomic Characteristics}

Among the 378 medical students who participated in this study, the mean age was 21.6 years with a range from 19 to 26 . Half of them were females $(50.8 \%)$, and most of the participants $(n=367,97.1 \%)$ were Saudi. Most of them were in the second year $(25.1 \%)$, and the fewest were from the fourth year (16.7\%). Most of the participants were single (93.7\%) and living in owned homes (70.6\%) with their families $(88.9 \%)$. Almost half of the participants (48.4\%) had a monthly income of more than 10,000 Saudi Reals (SR) per month. Current smokers made up 23.5\%, and $4.2 \%$ were ex-smokers. A total of $8.5 \%$ indicated they had a chronic illness, and $13.8 \%$ were taking medications. The mother's education levels were university degree, $37 \%$; secondary school, $30.2 \%$; diploma, $13.5 \%$; master's degree, $11.6 \%$; no formal education, $5.6 \%$; and others, $2.1 \%$. The father's education levels were university degree, $36.8 \%$; master's degree, $27.2 \%$; secondary school, $15.9 \%$; diploma, $14.3 \%$; PhD, 3.2\%; no formal education, $1.3 \%$; and others, $1.3 \%$. The parents were separated for
$12.4 \%$ of respondents, and the percentage of respondents who had working mothers was 37\%. Most of the respondents who played sports (59.3\%; see Table 1$)$.

\section{Eating Habits}

Around $30.7 \%$ of the students thought that they had healthy eating habits. Almost half of the participants (50.5\%) ate meals regularly, but only $34.7 \%$ had breakfast on a daily basis, and $18.5 \%$ had breakfast rarely. Only $17.7 \%$ of the participants reported that they ate meals without snacking in between, and $26.5 \%$ ate snacks daily, while $27.8 \%$ rarely had snacks. Around $20.4 \%$ of the participants consumed vegetables daily, while $14.3 \%$ ate vegetables only rarely. About $11.9 \%$ of the respondents consumed fruits on a daily basis, while $20.4 \%$ ate fruit rarely. Around $9.5 \%$ ate fried food on a daily basis, while $15.6 \%$ ate fried foods rarely. Relatively few (10.1\%) of the participants drank more than 2 liters of water per day. A majority of the participants $(50.8 \%)$ ate meals with family and friends one to four times per week, while $44.2 \%$ ate with their family and friends on a daily basis, and 5\% reported that they always ate alone. About two-thirds of the students (65.9\%) went to fast-food restaurants "sometimes," followed by $28.0 \%$ of students eating fast food "often," and 6.1\% never ate fast food. More than half $(53.7 \%)$ of the students knew that they should eat a variety of foods for balanced nutrition, although $32.0 \%, 7.1 \%$, and $5.6 \%$ of the students thought that "mainly vegetables," "mainly meat," or "mainly carbohydrates," respectively, was sufficient for balanced nutrition. Most of the participants typically ate a variety of foods (43.1\%), but $38.1 \%$ admitted to consuming predominantly meats. The mean of healthy habits score was 4.2, from a range of $0-10$ (Table 2 ).

\section{Psychological Factors Affecting Eating Behavior}

There were some participants who reported that they often ate because they felt lonely (10.1\%). Around $15.9 \%$ often felt completely out of control when it came to food, while $48.9 \%$ sometimes felt that way. In terms of overeating, $11.4 \%$ said they often ate until their stomach hurt, 55.3\% exhibited that same behavior sometimes, and the remaining third $33.3 \%$ had never eaten till their stomach hurt. When the respondents were asked if they eat when they are upset or nervous, most of them (43.1\%) answered "never." A majority of the participants said that they "sometimes" eat because of being bored $(51.1 \%)$ and "sometimes" because of being happy 
Table I Sociodemographic Characteristics of Participants $(n=378)$

\begin{tabular}{|c|c|}
\hline Demographic Data & Value \\
\hline Age (years) & $21.6 \pm 0.1(19.0-26.0)$ \\
\hline \multicolumn{2}{|l|}{ Gender } \\
\hline Female & $192(50.8 \%)$ \\
\hline Male & I 86 (49.2\%) \\
\hline \multicolumn{2}{|l|}{ Nationality } \\
\hline Saudi & 367 (97.1\%) \\
\hline Non-Saudi & $11(2.9 \%)$ \\
\hline \multicolumn{2}{|l|}{ Academic years } \\
\hline Second & $95(25.1 \%)$ \\
\hline Third & $70(18.5 \%)$ \\
\hline Fourth & $63(16.7 \%)$ \\
\hline Fifth & $80(21.2 \%)$ \\
\hline Sixth & 70 (I8.5\%) \\
\hline \multicolumn{2}{|l|}{ Marital status } \\
\hline Single & 354 (93.7\%) \\
\hline Married & $21(5.6 \%)$ \\
\hline Divorced & $3(0.8 \%)$ \\
\hline \multicolumn{2}{|l|}{ Residence } \\
\hline Own & 267 (70.6\%) \\
\hline Rent & III (29.4\%) \\
\hline \multicolumn{2}{|l|}{ Living arrangement } \\
\hline Living alone & $42(11.1 \%)$ \\
\hline Living with family & $336(88.9 \%)$ \\
\hline \multicolumn{2}{|l|}{ Monthly household income (SR) } \\
\hline$<3000 \mathrm{SR}$ & 124 (32.8\%) \\
\hline $3000-10,000$ SR & 71 (18.6\%) \\
\hline$>10,000 \mathrm{SR}$ & I 83 (48.4\%) \\
\hline \multicolumn{2}{|l|}{ Smoking } \\
\hline Never smoked & $273(72.2 \%)$ \\
\hline Ex-smoker & $16(4.2 \%)$ \\
\hline Current smoker & 89 (23.5\%) \\
\hline Smoking duration (years) & $4.1 \pm 0.3(1.0-13.0)$ \\
\hline \multicolumn{2}{|l|}{ Chronic illness } \\
\hline No & 346 (91.5\%) \\
\hline Yes & $32(8.5 \%)$ \\
\hline \multicolumn{2}{|l|}{ Taking medications } \\
\hline No & $326(86.2 \%)$ \\
\hline Yes & $52(13.8 \%)$ \\
\hline Number of family members & $6.2 \pm 0.1(1.0-13.0)$ \\
\hline \multicolumn{2}{|l|}{ Mother's education level } \\
\hline University degree & I 40 (37.0\%) \\
\hline Secondary school & II 4 (30.2\%) \\
\hline Diploma & $51(13.5 \%)$ \\
\hline
\end{tabular}

(Continued)
Table I (Continued).

\begin{tabular}{|l|l|}
\hline Demographic Data & Value \\
\hline Master's degree & $44(11.6 \%)$ \\
No formal education & $21(5.6 \%)$ \\
Others & $8(2.1 \%)$ \\
\hline Father's education level & \\
University degree & $139(36.8 \%)$ \\
Master's degree & $103(27.2 \%)$ \\
Secondary school & $60(15.9 \%)$ \\
Diploma & $54(14.3 \%)$ \\
PhD & $12(3.2 \%)$ \\
No formal education & $5(1.3 \%)$ \\
Others & $5(1.3 \%)$ \\
\hline Parents separated & \\
No & $331(87.6 \%)$ \\
Yes & $47(12.4 \%)$ \\
\hline Mother works & \\
No & $238(63.0 \%)$ \\
Yes & $140(37.0 \%)$ \\
\hline Plays sports & $154(40.7 \%)$ \\
No & $224(59.3 \%)$ \\
\hline Yes & \\
\hline Number of days with regular exercise & \\
per week & $118(31.2 \%)$ \\
Once & \\
Twice & \\
\hline More than twice & \\
\hline
\end{tabular}

Note: Data were expressed as mean +/- standard error of mean (minimum-maximum) or number (\%) as appropriate.

Abbreviation: SR, Saudi Real, I Dollar=3.75 SR.

(56.6\%). Boredom and happiness were not found to be associated with eating for $27.5 \%$ and $24.6 \%$ of respondents, respectively (Table 3 ).

\section{Relationship Between Eating Patterns and Sociodemographic Factors}

The total eating score was compared throughout the categorical variables and found to be significant for the following factors: different academic years, with the highest scores in the sixth year and the lowest score in the fifth year $(P<0.0001)$. Those who lived in an owned place had higher scores than those who lived in a rented place (4.46 \pm 0.12 versus $3.73 \pm 0.19, P<0.001)$. Living arrangements were another significant factor and showed that students who lived with their families had higher scores than the students who were living alone ( $4.35 \pm 0.11$ versus 3.43 $\pm 0.28, P=0.005$ ). Another significant factor was smoking, 
Table 2 Eating Habits Among Respondents $(n=378)$

\begin{tabular}{|c|c|}
\hline Characteristics & Value \\
\hline \multicolumn{2}{|l|}{ Healthy eating habits } \\
\hline No & $262(69.3 \%)$ \\
\hline Yes & $116(30.7 \%)$ \\
\hline \multicolumn{2}{|l|}{ QI. Regular meals } \\
\hline Yes & $19 \mid(50.5 \%)$ \\
\hline No & $187(49.5 \%)$ \\
\hline \multicolumn{2}{|l|}{ Q2. Frequency of having daily breakfast } \\
\hline I-2 times per week & 78 (20.8\%) \\
\hline 3-4 times per week & 99 (26.2\%) \\
\hline Daily & $13 \mid(34.7 \%)$ \\
\hline Rarely & $70(18.5 \%)$ \\
\hline \multicolumn{2}{|l|}{$\begin{array}{l}\text { Q3. Frequency of having meals without } \\
\text { snacks in between }\end{array}$} \\
\hline I-2 times per week & $98(25.9 \%)$ \\
\hline 3-4 times per week & $108(28.6 \%)$ \\
\hline Daily & $67(17.7 \%)$ \\
\hline Rarely & $105(27.8 \%)$ \\
\hline \multicolumn{2}{|l|}{ Q4. Frequency of having snacks } \\
\hline I-2 times per week & 81 (21.4\%) \\
\hline 3-4 times per week & $128(33.9 \%)$ \\
\hline Daily & $100(26.5 \%)$ \\
\hline Rarely & $69(18.3 \%)$ \\
\hline \multicolumn{2}{|l|}{ Q5. Weekly consumption of vegetables } \\
\hline I-2 times per week & $134(35.4 \%)$ \\
\hline 3-4 times per week & $113(29.9 \%)$ \\
\hline Daily & 77 (20.4\%) \\
\hline Rarely & $54(14.3 \%)$ \\
\hline \multicolumn{2}{|l|}{ Q6. Weekly consumption of fruits } \\
\hline I-2 times per week & $155(41.0 \%)$ \\
\hline 3-4 times per week & $101(26.7 \%)$ \\
\hline Daily & 45 (11.9\%) \\
\hline Rarely & 77 (20.4\%) \\
\hline \multicolumn{2}{|l|}{ Q7. Weekly consumption of fried food } \\
\hline I-2 times per week & $140(37.0 \%)$ \\
\hline 3-4 times per week & $143(37.8 \%)$ \\
\hline Daily & $36(9.5 \%)$ \\
\hline Rarely & $59(15.6 \%)$ \\
\hline \multicolumn{2}{|l|}{ Q8. Water intake (liters/day) } \\
\hline$<$ I liter & $101(26.7 \%)$ \\
\hline I-I.5 liter & $156(4 \mid .3 \%)$ \\
\hline I.5-2 liter & $83(22.0 \%)$ \\
\hline$>2$ liters & $38(10.1 \%)$ \\
\hline \multicolumn{2}{|l|}{ Q9. Meals with family and friends } \\
\hline I-2 per week & $63(16.7 \%)$ \\
\hline 3-4 times per week & $129(34.1 \%)$ \\
\hline Always alone & $19(5.0 \%)$ \\
\hline
\end{tabular}

(Continued)
Table 2 (Continued).

\begin{tabular}{|l|l|}
\hline Characteristics & Value \\
\hline Daily & $167(44.2 \%)$ \\
\hline QIO. Fast food in restaurants & \\
Never & $23(6.1 \%)$ \\
Often & $106(28.0 \%)$ \\
Sometimes & $249(65.9 \%)$ \\
\hline QII. Food type with balanced nutrition & \\
All of them & $1(0.3 \%)$ \\
All types but not fried & $1(0.3 \%)$ \\
Balanced nutrition needs to be contained & $\mathrm{I}(0.3 \%)$ \\
with carbs, proteins, and fats & $21(5.6 \%)$ \\
Carbohydrate (rice, bread) & $1(0.3 \%)$ \\
Cover your requirements from macros & $1(0.3 \%)$ \\
Daily needs of carbs, proteins, and fats & $1(0.3 \%)$ \\
Fruits & $27(7.1 \%)$ \\
Mainly meat & $121(32.0 \%)$ \\
Mainly vegetables & $203(53.7 \%)$ \\
Variety of foods & \\
\hline QI2. Type of food most often ordered & $7(1.9 \%)$ \\
Pasta, French fries & $48(12.7 \%)$ \\
Carbohydrates (rice, bread, etc.) & $\mathrm{I}(0.3 \%)$ \\
Chicken & $\mathrm{I}(0.3 \%)$ \\
Fatty food, ketogenic diet & $144(38.1 \%)$ \\
Predominantly meat & $14(3.7 \%)$ \\
Predominantly vegetable & $163(43.1 \%)$ \\
Variety of food & $4.2 \pm 0.1(0.0-10.0)$ \\
\hline Healthy habits score & \\
\hline
\end{tabular}

Note: Data were expressed as mean $+/$ - standard error of mean (minimum-maximum) or number (\%), as appropriate.

where students who had never smoked had higher scores (4.56 \pm 0.12$)$ than the ex-smokers $(4.50 \pm 0.63)$ and current smokers (3.23 \pm 0.19$)$, with $P<0.0001$ for all. The score was significantly higher among students whose parents were not separated as compared to those whose parents were separated ( $4.33 \pm 0.11$ vs. $3.62 \pm 0.27, P=0.023)$ and for students playing sports versus those did not play a sport $(4.55 \pm 0.14$ vs. $3.80 \pm 0.14, P=0.0001)$. For all other factors, including gender, nationality, academic year, marital status, father's and mother's education levels, and mother's working status, there were no significant differences found in the scores between the groups (Table 4).

\section{Relationship Between Eating Patterns and Psychological Factors}

There was a significant difference found between groups for the scores on each of the questions regarding psychological 
Table 3 Psychological Factors Related to Eating Behavior $(n=378)$

\begin{tabular}{|l|l|l|l|}
\hline \multirow{2}{*}{ Psychological Factors } & \multicolumn{2}{|l|}{ Answer Level } \\
\cline { 2 - 4 } & Never & Often & Sometimes \\
\hline $\begin{array}{l}\text { Eat because of feeling lonely } \\
\text { Feel completely out of control } \\
\text { when it comes to food }\end{array}$ & $171(45.2 \%)$ & $38(10.1 \%)$ & $169(44.7 \%)$ \\
$\begin{array}{l}\text { Eat so much until stomach } \\
\text { hurts }\end{array}$ & $126(33.2 \%)$ & $60(15.9 \%)$ & $185(48.9 \%)$ \\
$\begin{array}{l}\text { Eat because of feeling upset or } \\
\text { nervous }\end{array}$ & $163(43.1 \%)$ & $56(14.8 \%)$ & $159(42.1 \%)$ \\
$\begin{array}{l}\text { Eat because of feeling bored } \\
\text { Eat because of feeling happy }\end{array}$ & $104(27.5 \%)$ & $81(21.4 \%)$ & $193(51.1 \%)$ \\
$93(24.6 \%)$ & $71(18.8 \%)$ & $214(56.6 \%)$ \\
\hline
\end{tabular}

Note: Data were expressed as number (\%).

factors. The students who answered "never" to the questions had higher scores than those who answered "often" or "sometimes." The mean score for those who never ate because they felt lonely was higher than those who ate often or sometimes $(4.65 \pm 0.16$ vs. $3.23 \pm 0.26$ and 4.04 $\pm 0.15, P<0.0001)$. The mean score for the students who never felt completely out of control when it comes to food was $4.85 \pm 0.19$, while for those who did often feel out of control with food was $3.75 \pm 0.22$, and for those who sometimes felt out of control was $3.97 \pm 0.14$, with significant differences between them $(P<0.0001)$. The mean score for the respondents who had eaten until their stomach hurt was $4.90 \pm 0.12$, while for those who did that often was $3.84 \pm 0.29$ and those who sometimes did was $393 \pm 0.12$ with significant differences between them $(P<0.0001)$. The mean score of the respondents who ate because they were upset or nervous was $4.52 \pm 0.16$, while for those who did that often and sometimes were, respectively, $3.79 \pm 0.24$ and $4.13 \pm 0.16$ $(P=0.041)$. The score for students who never ate because they were bored was $4.89 \pm 0.22$, while for those who often ate because they were bored was $3.75 \pm 0.18$, and those who only ate out of boredom sometimes was $4.10 \pm 0.14$ $(P<0.0001)$ (Table 5).

\section{Discussion}

The present study aimed to evaluate eating habits and investigate the relationships between sociodemographic, socioeconomic, and psychological factors with eating habits among medical students at a Saudi Arabian university. Most of the participants were Saudi (97.1\%), single (93.7\%), lived with family $(88.9 \%)$, and were nonsmokers $(72.2 \%)$, which may be a good representative
Table 4 Association Between Eating Habits and Sociodemographic Factors $(n=378)$

\begin{tabular}{|c|c|c|}
\hline Characteristics & Mean \pm SE & P-value \\
\hline Gender & & 0.165 \\
\hline Male & $4.10 \pm 0.14$ & \\
\hline Female & $4.39 \pm 0.15$ & \\
\hline Nationality & & 0.107 \\
\hline Saudi & $4.22 \pm 0.0$ & \\
\hline Non-Saudi & $5.09 \pm 0.65$ & \\
\hline Academic year & & $<0.0001$ \\
\hline Second & $4.08 \pm 0.22$ & \\
\hline Third & $4.54 \pm 0.23$ & \\
\hline Fourth & $4.22 \pm 0.23$ & \\
\hline Fifth & $3.35 \pm 0.19$ & \\
\hline Sixth & $5.20 \pm 0.23$ & \\
\hline Marital status & & 0.254 \\
\hline Single & $4.25 \pm 0.12$ & \\
\hline Married & $4.33 \pm 0.52$ & \\
\hline Divorced & $2.33 \pm 0.88$ & \\
\hline Residence & & $<0.001$ \\
\hline Own & $4.46 \pm 0.12$ & \\
\hline Rent & $3.73 \pm 0.19$ & \\
\hline Living arrangement & & 0.005 \\
\hline Live alone & $3.43 \pm 0.28$ & \\
\hline Live with family & $4.35 \pm 0.11$ & \\
\hline Monthly household income (SR) & & 0.069 \\
\hline$<3000$ & $4.19 \pm 0.20$ & \\
\hline $3000-10,000$ & $3.80 \pm 0.22$ & \\
\hline$>10,000$ & $4.45 \pm 0.14$ & \\
\hline Smoking & & $<0.0001$ \\
\hline Current smoker & $3.23 \pm 0.19$ & \\
\hline Ex-smoker & $4.50 \pm 0.63$ & \\
\hline Never smoked & $4.56 \pm 0.12$ & \\
\hline Mother's education level & & 0.484 \\
\hline Secondary school & $4.16 \pm 0.20$ & \\
\hline Diploma & $4.7 \mid 8 \pm 0.31$ & \\
\hline University degree & $4.16 \pm 0.15$ & \\
\hline Master's degree & $4.84 \pm 0.33$ & \\
\hline No formal education & 4. $10 \pm 0.46$ & \\
\hline Others & $4.38 \pm 0.42$ & \\
\hline Father's education level & & 0.614 \\
\hline Secondary school & $4.23 \pm 0.24$ & \\
\hline Diploma & $4.35 \pm 0.28$ & \\
\hline Degree & $3.99 \pm 0.18$ & \\
\hline Master's & $4.52 \pm 0.20$ & \\
\hline No formal education & $4.20 \pm 0.73$ & \\
\hline $\mathrm{PhD}$ & $4.50 \pm 0.51$ & \\
\hline Others & $4.20 \pm 0.86$ & \\
\hline
\end{tabular}

(Continued) 
Table 4 (Continued).

\begin{tabular}{|l|l|l|}
\hline Characteristics & Mean \pm SE & P-value \\
\hline Parents separated & & 0.023 \\
No & $4.33 \pm 0.11$ & \\
Yes & $3.62 \pm 0.27$ & \\
\hline Mother works & & 0.955 \\
No & $4.25 \pm 0.13$ & \\
Yes & $4.24 \pm 0.17$ & \\
\hline Plays sports & & 0.0001 \\
No & $3.80 \pm 0.14$ & \\
Yes & $4.55 \pm 0.14$ & \\
\hline
\end{tabular}

Notes: Data were expressed as mean $+/$ - standard error of mean. Significance was determined by either an unpaired Student's t-test or one-way ANOVA test, as appropriate.

Table 5 Association Between Eating Habits and Psychological Factors $(n=378)$

\begin{tabular}{|l|l|l|}
\hline Psychological Factors & Mean \pm SE & P-value \\
\hline Eat because of feeling lonely & & $<0.000$ I \\
$\quad$ Never & $4.65 \pm 0.16$ & \\
Often & $3.32 \pm 0.26$ & \\
Sometimes & $4.04 \pm 0.15$ & \\
\hline Feel completely out of control when it & & $<0.000$ I \\
comes to food & & \\
Never & $4.85 \pm 0.19$ & \\
Often & $3.75 \pm 0.22$ & \\
Sometimes & $3.97 \pm 0.14$ & \\
\hline Eat so much until stomach hurts & & $<0.0001$ \\
Never & $4.90 \pm 0.21$ & \\
Often & $3.84 \pm 0.29$ & \\
Sometimes & $3.93 \pm 0.12$ & \\
\hline Eat because of feeling upset or nervous & & 0.041 \\
Never & $4.52 \pm 0.16$ & \\
Often & $3.79 \pm 0.24$ & \\
Sometimes & $4.13 \pm 0.16$ & \\
\hline Eat because of feeling bored & & $<0.0001$ \\
Never & $4.89 \pm 0.22$ & \\
Often & $3.75 \pm 0.18$ & \\
Sometimes & $4.10 \pm 0.14$ & \\
\hline Eat because of feeling happy & & 0.065 \\
Never & $3.65 \pm 0.23$ & \\
Often & $4.16 \pm 0.13$ & \\
Sometimes & & \\
\hline
\end{tabular}

Notes: Data were expressed as mean $+/$ - standard error of mean. Significance was determined by one-way ANOVA test.

sample of all undergraduate medical students in Saudi Arabia. In Dammam, Saudi Arabia, Al-Qahtani ${ }^{10}$ reported high numbers of single medical students $(90 \%)$, although
$76 \%$ of the students who lived with their families and were single were more likely to choose unhealthy foods. ${ }^{16}$

In the present study, the participants' parents were highly educated, and only $1.3 \%$ of fathers and $5.6 \%$ of mothers had no formal education. Al-Qahtani ${ }^{10}$ reported that $>90 \%$ of the students' parents had high-level degrees, and that had a positive impact on their children's eating patterns; ${ }^{17}$ however, that effect was not shown in this study, where most students had unhealthy dietary patterns in spite of their parents' high education levels.

In this study, the majority of students (88.9\%) lived with family, and the healthy habits score was significantly higher in students who lived with their family than those who lived alone. Living with family appeared to be a good environment to protect against bad dietary patterns. ${ }^{16}$

In this study, only $23.5 \%$ of the medical students were current smokers. The total health habit score was significantly higher for non-smokers than for current or former smokers. Abstinence from smoking was found to be positively associated with healthy eating habits in this study. In other studies, smoking was correlated with bad eating habits among Chinese university students ${ }^{9}$ and Malaysian medical students. ${ }^{14}$

In this study, $59.3 \%$ of the students exercised regularly, with $31.2 \%$ exercising more than twice per week. Physical activity is very important for health; in comparison to international studies, Saudi youth had more physical inactivity and sedentary lifestyles. ${ }^{18}$ In this respect, AlNakeeb et $\mathrm{al}^{19}$ reported that physical activity among young females and males (26\%) from Al-Ahsa (Eastern region of Saudi Arabia) was low when compared to adolescents in Coventry (77.2\%) and Birmingham (72.3\%) in the United Kingdom.

University students experience changes in their life patterns and acquire unhealthy eating habits. This transition begins in school and university and may remain later in life. ${ }^{1}$ Almost half of the students in this study (50.5\%) ate regular meals; this finding was higher than those reported in other areas of Saudi Arabia, from the College of Health Sciences at Rass, Qassim University $(36.7 \%)^{20}$ and from Abha $(31.0 \%){ }^{21}$ Meanwhile, this finding was lower than that documented for Chinese $(83.6 \%),{ }^{9}$ Lebanese $(61.4 \%),{ }^{22}$ and Malaysian medical students $(57.6 \%){ }^{14}$ These habits need to be changed through educational programs aimed at enhancing healthy eating habits in Saudi Arabia.

Breakfast is widely considered to be the most important meal of the day. ${ }^{23}$ It is defined as any food eaten 
before or at the start of daily activities, within $2 \mathrm{hrs}$ of waking, and typically not after 10:00 am. ${ }^{24}$ Breakfast skipping was defined as eating breakfast fewer than 7 days per week. ${ }^{25}$ Although medical students were expected to have this knowledge, only about one-third $(34.7 \%)$ of study participants ate breakfast on a daily basis in the present study. Breakfast skipping was found in about $15 \%$ of Saudi secondary school students from Jeddah, ${ }^{26} 49 \%$ of Saudi adolescents from Abha, ${ }^{18}$ and $10 \%$ of young males and $19 \%$ of females in the United Arab Emirates. ${ }^{27}$ Our finding was slightly higher than that reported in Lebanon $(31.8 \%){ }^{22}$ Meanwhile, studies from Malaysia reported a rising trend toward daily breakfast eating among female youth in Pahang (52.6\%), ${ }^{28}$ Malay undergraduate students in Selangor $(75.6 \%),{ }^{29}$ and medical students in private university in Malaysia (43.9\%). ${ }^{14}$ Regular breakfast eating is essential for medical students to have enough energy intake to get over the malaise caused by a rigorous program of daily studies. ${ }^{30}$ Commonly reported causes for skipping breakfast were lack of time, oversleeping, lack of appetite, disliking eating early in the morning, concerns about excess body weight, living alone, and lack of parental control. ${ }^{25,31}$ Breakfast consumption is associated with several advantages for behavioral, cognitive, and affective aspects. ${ }^{32}$ Furthermore, skipping breakfast is a risk factor for obesity due to overeating at the next meal, leading to high serum cholesterol levels and type 2 diabetes mellitus. ${ }^{33}$

This study revealed that only $17.7 \%$ of the students ate meals on a daily basis without having snacks in between, while a majority (56.3\%) had snacks between meals at least three times per week, and $26.5 \%$ had snacks daily. Daily consumption of snacks was also a common habit $(35.96 \%)$ among the Saudi students in Abha, ${ }^{21}$ and being a staple food in this region, dates were eaten by students typically around four times per week (29.21\%). The findings of this study were higher compared to previous studies from various other countries, where fewer Syrian $(53 \%),{ }^{34}$ Lebanese $(53.20 \%),{ }^{22}$ and Malaysian $(42.4 \%)^{14}$ students consumed snacks regularly. Frequent eating of snacks is a common habit among young people. ${ }^{2,35}$ Further, in both lean and obese people, frequent snacking may lead to slower weight loss or even weight gain. ${ }^{36}$

This study revealed that the proportion of medical students who consumed vegetables and fruits daily was $20.4 \%$ and $11.9 \%$, respectively. A prior study conducted in Saudi Arabia among university students showed that $22 \%$ of them consumed at least five servings of vegetables per day. ${ }^{37}$ In
Abha, Saudi Arabia, the reported prevalence of fruits and vegetables intake among Saudi youth were 50.8\% and $62.4 \%$, ${ }^{4}$ respectively, and for fruit intake among Saudi university students, it was $31.46 \%{ }^{21}$ Aboul Azm and Elebiary ${ }^{38}$ reported that $30 \%$ of female nursing students in Saudi Arabia ate fruits and vegetables daily. Research in other countries have reported that $26.3 \%$ of Bahrain students ate five servings of fruits and vegetables daily, ${ }^{35}$ while $20 \%$ of Pakistani female university students ate two servings of fruits and vegetables daily. ${ }^{39}$ Moreover, vegetable and fruit consumption more than three times per week for adolescent males and females in the United Arab Emirates was reported to range from $49 \%$ to $69 \%{ }^{27}$ Western countries such as the United States, ${ }^{3}$ Germany, ${ }^{40}$ and Great Britain ${ }^{41}$ revealed between $66 \%$ and $95 \%$ of university students did not meet recommendations for daily vegetable and fruit consumption. Chourdakis et $\mathrm{al}^{42}$ revealed that more than half of students reported consumption of vegetables and fruits at least three times per week among medical students in northern Greece. Meanwhile, a study from Malaysia revealed 19\% of university students ate vegetables more than three times per week. ${ }^{8}$

The World Health Organization recommendations are that adults should eat a minimum of five servings, or $4000 \mathrm{~g}$, of vegetables and fruits daily. ${ }^{43}$ In Saudi Arabia, dietary recommendations that originate from the Ministry of Health as the Healthy Palm Saudi dietary guidelines (Alnakhala Elgethaiya), aimed at enhancing the consumption of healthier diets recommend eating three to five servings of vegetables and two to four servings of fruits on a daily basis. ${ }^{44}$ Adequate consumption of vegetables and fruits protects against chronic diseases like cardiovascular diseases, obesity, and some cancer types. ${ }^{45}$

Students usually choose fast food due to its availability, taste, convenience, and low costs. ${ }^{46}$ This study showed that $37 \%$ of students ate fried food one to two times per week, and $37.8 \%$ eat it three to four times per week. This study also showed that most of respondents $(65.9 \%)$ ate fried foods at restaurants, which concurs with other studies. $^{22}$ In Riyadh, the average frequency of fast-food consumption was 4.5 times per week among youth. ${ }^{47}$ A Malaysian study revealed that $73.5 \%$ of medical students consumed fast food more than two times per week. ${ }^{14}$

In Damascus, Syria, only $14 \%$ of adolescents ate fast foods more than four times per week. ${ }^{2}$ Chin and Nasir ${ }^{28}$ revealed that only $4.7 \%$ of students went to fast-food restaurants in Pahang, Malaysia. Westernization, which has resulted in nutrition changes, has had a major effect on the increased risk of unhealthy lifestyles in Arab 
countries. ${ }^{48}$ Fast food rich in fat and physical inactivity were found to be risk factors for coronary heart disease among Saudi male university students at Dammam City ${ }^{49}$ and in clinical years male medical students at KAU. ${ }^{50}$

Most of the participants of the present study ate their meals with family and friends on a daily basis (44.2\%), which was slightly higher than that reported for Lebanese university students $(42.7 \%),{ }^{22}$ but lower than what has been reported for Malaysian medical students $(81.80 \%){ }^{14}$

Stress is considered a general body response that affects the body's ability to maintain homeostasis. Stress is a global problem due to its negative impact on human health. ${ }^{51}$ Many researchers have stated that medical students have significant amounts of stress throughout their years of university life. ${ }^{52,53}$ The results of this study revealed that many students eat because of negative emotions like feeling lonely (44.7\%), nervous $(42.1 \%)$, or bored $(51.1 \%)$. Conversely, others sometimes eat due to feeling happy $(56.6 \%)$. The stressful lifestyles of medical students may be a contributing factor for negative emotions, and these rates were supported by the eating habit scores exhibited in this study, which are significantly higher for students who responded "never" to various psychological questions such as, Do you eat because of feeling lonely? Do you feel completely out of control when it comes to food? Do you eat so much that your stomach hurts? Do you eat because you are feeling upset or nervous? Do you eat because you are bored? And Do you eat because you are happy? Former studies reported that the behavioral effects of stress might influence eating patterns, where people living in a stressful environment consumed more food as a way of coping with the stress. ${ }^{54}$

The association between stress and eating habits in medical students has previously been studied in different populations. $^{10,55,56}$ Several researchers have shown a prevalence of stress among medical students, ranging from $28.9 \%$ to $61.4 \%$ in Saudi Arabia, Egypt, the United Kingdom, Malaysia, and Thailand. ${ }^{57-60}$ In the present study, the eating habits scores were lower for those who answered yes to the questions whether they ate because of feeling lonely, ate until their stomach hurt, ate because of feeling upset or nervous, and ate because of feeling bored. Stress in medical students may be due to workloads, the commuting distance between home and the university, and the result of incorrect homework assignments without any specific and clear solutions offered. ${ }^{14,61}$ In a study conducted in Kuwait, Ahmed et al revealed that stress is highly associated with unhealthy food selection. ${ }^{62}$ For some students, these situations can generate stress that affects the appetite and they skip meals. They will show unhealthy eating behaviors, consuming fast food, food that are high in fats, sweets, and soft drinks. ${ }^{62}$ The development of new strategies in medical schools that aim at reducing stress will be positive for student health. ${ }^{63}$ The eating habits modified by stress need to be reversed, with the aim of producing a positive impact and better health for the students in their studies. ${ }^{51}$

In the present study, most of the students (53.7\%) reported that a balanced diet was one that contains a variety of foods. In Abha, Saudi Arabia, most of the students $(65.62 \%)$ knew what constitutes a balanced diet. ${ }^{21}$ A study at Midwestern University in the state of Arizona in the United States among 181 female and 105 male students revealed that $94.4 \%$ of the students agreed that it is important to eat different types of food for better health. ${ }^{64}$ In another study, healthful food was known to be foods that contain more vegetables and fruits and are low in fat content. ${ }^{65}$

\section{Limitations}

This study design was cross-sectional, which does not allow for establishing causal relationships. Another limitation of this study is the absence of anthropometric measurements from the students. In addition, the students in this study were from just one medical college, and therefore, they may not be representative of all university medical students in Saudi Arabia.

\section{Conclusion}

Most medical students had unhealthy dietary habits and physical inactivity. The unhealthy dietary habits were irregular meals, inadequate consumption of fruits and vegetables, and eating too many fried and fast foods. Socioeconomic and psychological aspects were significantly affected by the eating habits of the students. Nutritional education for medical students should be improved to enhance healthy eating habits and lifestyles, along with adherence to healthier diets. Future studies are recommended to use larger sample sizes and include students from different medical universities in Saudi Arabia.

\section{Statement of Ethics}

All procedures performed in studies involving human participants were in accordance with the ethical standards of the institutional and/or national research committee and with the 1964 Helsinki declaration and its later amendments or comparable ethical standards. Ethical Approval ref. No. 244-1441. The protocol of the present study was approved by the Research Ethics Committee of KAU, 
Jeddah, Saudi Arabia. All participants were informed about the nature of the study and the confidentiality of their responses. Answering the online questionnaire was considered consent to participate.

\section{Data Sharing Statement}

The authors declare that they had full access to all of the data in this study, and the authors take complete responsibility for the integrity of the data and the accuracy of the data analysis. All original data are available in the Department of Family Medicine, KAU, Jeddah, Saudi Arabia. Data used to support the findings of this study are available from the corresponding author upon request.

\section{Acknowledgment}

The authors are thankful to the students of KAU for their participation in this study.

\section{Author Contributions}

All authors contributed to the study design, data collection and analysis, drafting and revising of the manuscript, and all authors gave final approval of the version to be published. In addition, all authors agree to be accountable for all aspects of the work.

\section{Funding}

This work was funded by the Deanship of Scientific Research (DSR), KAU, Jeddah, under grant No. DF-339140-1441. The authors acknowledge DSR with thanks for their technical and financial support.

\section{Disclosure}

No authors have any conflicts of interest to declare.

\section{References}

1. Nelson MC, Story M, Larson NI, Neumark-Sztainer D, Lytle LA. Emerging adulthood and college-aged youth: an overlooked age for weight-related behavior change. Obesity. 2008;16(10):2205-2211. doi:10.1038/oby.2008.365

2. Musaiger AO, Kalam F. Dietary habits and lifestyle among adolescents in Damascus, Syria. Ann Agric Environ Med. 2014;21:2. doi:10.5604/ 1232-1966.1108616

3. King KA, Mohl K, Bernard AL, Vidourek RA. Does involvement in healthy eating among university students differ based on exercise status and reasons for exercise? Calif J Health Promot. 2007;5 (3):106-119. doi:10.32398/cjhp.v5i3

4. Mahfouz AA, Abdelmoneim I, Khan MY, et al. Obesity and related behaviors among adolescent school boys in Abha City, Southwestern Saudi Arabia. J Trop Pediatr. 2007;54(2):120-124. doi:10.1093/tropej/ fmm089
5. Al-Hazzaa HM, Abahussain NA, Al-Sobayel HI, Qahwaji DM, Musaiger AO. Physical activity, sedentary behaviors and dietary habits among Saudi adolescents relative to age, gender and region. Int J Behav Nutr Phys Act. 2011;8(1):140. doi:10.1186/1479-5868$8-140$

6. Adam A, Osama S, Muhammad KI. Nutrition and food consumption patterns in the Kingdom of Saudi Arabia. Pak J Nutr. 2014;13 (4):181. doi:10.3923/pjn.2014.181.190

7. Sogari G, Velez-Argumedo C, Gómez M, Mora C. College students and eating habits: a study using an ecological model for healthy behavior. Nutrients. 2018;10(12):1823. doi:10.3390/nu10121823

8. Gan WY, Mohn NM, Zalilah MS, Hazizi AS. Differences in eating behaviours, dietary intake and body weight status between male and female Malaysian University students. Malays J Nutr. 2011;17 (2):213-228.

9. Sakamaki R, Toyama K, Amamoto R, Liu C-J, Shinfuku N. Nutritional knowledge, food habits and health attitude of Chinese university students-a cross sectional study. BMC Nutr. 2005;4(1):4.

10. Al-Qahtani MH. Dietary habits of Saudi medical students at University of Dammam. Int J Health Sci. 2016;10(3):353-362.

11. Mikolajczyk RT, El Ansari W, Maxwell AE. Food consumption frequency and perceived stress and depressive symptoms among students in three European countries. BMC Nutr. 2009;8(1):31.

12. Tian-Ci Quek T, Tam W-S, Tran BX, et al. The global prevalence of anxiety among medical students: a meta-analysis. Int J Environ Res Public Health. 2019;16(15):2735. doi:10.3390/ijerph16152735

13. De La Cruz N, Crookston B, Dearden K, et al. Who sleeps under bednets in Ghana? A doer/non-doer analysis of malaria prevention behaviours. Malar J. 2006;5(1):61. doi:10.1186/1475-2875-5-61

14. Ganasegeran K, Al-Dubai SA, Qureshi AM, Al-Abed A-AA, Rizal A, Aljunid SM. Social and psychological factors affecting eating habits among university students in a Malaysian medical school: a cross-sectional study. BMC Nutr. 2012;11(1):48.

15. Kagan DM, Squires RL. Compulsive eating, dieting, stress, and hostility among college students. J Coll Stud Personnel. 1984;25 (3):213-220.

16. El Ansari W, Stock C, Mikolajczyk RT. Relationships between food consumption and living arrangements among university students in four European countries-a cross-sectional study. BMC Nutr. 2012;11 (1):28.

17. El-Mouzan MI, Al-Salloum AA, Al-Herbish AS, Qurachi MM, AlOmar AA. Effects of education of the head of the household on the prevalence of malnutrition in children. Saudi Med J. 2010;31 (3):304-307.

18. Farghaly NF, Ghazali BM, Al-Wabel HM, Sadek AA, Abbag FI. Life style and nutrition and their impact on health of Saudi school students in Abha, Southwestern region of Saudi Arabia. Saudi Med J. 2007;28 (3):415-421.

19. Al-Nakeeb Y, Lyons M, Collins P, et al. Obesity, physical activity and sedentary behavior amongst British and Saudi youth: a cross-cultural study. Int J Environ Res Public Health. 2012;9(4):1490-1506. doi:10.3390/ijerph9041490

20. Al-Rethaiaa AS, Fahmy A-EA, Al-Shwaiyat NM. Obesity and eating habits among college students in Saudi Arabia: a cross sectional study. BMC Nutr. 2010;9(1):39.

21. Alshahrani MM, Chandramohan S. A cross-sectional study on prevalence of obesity and its association with dietary habits among college students in Abha, Saudi Arabia. Int J Community Med Public Health. 2017;4(5):1406-1412. doi:10.18203/2394-6040.ijcmph20171747

22. Rizk S, Yahia N, Achkar A, Abdallah A. Eating habits and obesity among Lebanese university students. Nutr J. 2008;7:32.

23. Ahadi Z, Qorbani M, Kelishadi R, et al. Association between breakfast intake with anthropometric measurements, blood pressure and food consumption behaviors among Iranian children and adolescents: the CASPIAN-IV study. Public Health. 2015;129(6):740-747. doi:10.1016/j.puhe.2015.03.019 
24. Giovannini M, Verduci E, Scaglioni S, et al. Breakfast: a good habit, not a repetitive custom. J Int Med Res. 2008;36(4):613-624. doi: $10.1177 / 147323000803600401$

25. Moy F, Johari S, Ismail Y, Mahad R, Tie F, Wan ismail WA. Breakfast skipping and its associated factors among undergraduates in a public university in Kuala Lumpur. Malays J Nutr. 2009;15(2):165-174.

26. Abalkhail B, Shawky S. Prevalence of daily breakfast intake, iron deficiency anaemia and awareness of being anaemic among Saudi school students. Int J Food Sci Nutr. 2002;53(6):519-528. doi:10.1080/09637480220164370

27. bin Zaal A, Musaiger A, D’Souza R. Dietary habits associated with obesity among adolescents in Dubai, United Arab Emirates. Nutr Hosp. 2009;24(4):437-444.

28. Chin Y, Mohd Nasir M. Eating behaviors among female adolescents in Kuantan district, Pahang, Malaysia. Pak J Nutr. 2009;8 (4):425-432. doi:10.3923/pjn.2009.425.432

29. Isa KAM, Masuri MG. The association of breakfast consumption habit, snacking behavior and body mass index among university students. Am J Food Nutr. 2011;1(2):55-60. doi:10.5251/ ajfn.2011.1.2.55.60

30. Tanaka M, Mizuno K, Fukuda S, Shigihara Y, Watanabe Y. Relationships between dietary habits and the prevalence of fatigue in medical students. Nutrition. 2008;24(10):985-989. doi:10.1016/j. nut.2008.05.003

31. Ozdogan Y, Ozcelik AO, Surucuoglu MS. The breakfast habits of female university students. Pak J Nutr. 2010;9(9):882-886. doi:10.3923/pjn.2010.882.886

32. Ramli NN, Appukutty M. Breakfast consumption association with body status and physical activity among female university students. Malaysian J Mov Health Exercise. 2018;7(2). doi:10.15282/mohe. v7i2.229

33. Alam P. Nutritional status and eating practices among university students in selected universities in Selangor, Malaysia. Asian J Clin Nutr. 2012;4(3):77-87. doi:10.3923/ajen.2012.77.87

34. Bashour H. Survey of dietary habits of in-school adolescents in Damascus, Syrian Arab Republic. East Mediterr Health J. 2004;10 (6):853-862.

35. Musaiger A, Bader Z, Al-Roomi K, D'souza R. Dietary and lifestyle habits amongst adolescents in Bahrain. Food Nutr Res. 2011;55 (1):7122. doi:10.3402/fnr.v55i0.7122

36. Aparicio A, Rodríguez-Rodríguez E, Aranceta-Bartrina J, et al. Differences in meal patterns and timing with regard to central obesity in the ANIBES ('Anthropometric data, macronutrients and micronutrients intake, practice of physical activity, socioeconomic data and lifestyles in Spain') Study-CORRIGENDUM. Public Health Nutr. 2017;20(13):2364-2373. doi:10.1017/S1368980017000635

37. Al-Otaibi HH. The pattern of fruit and vegetable consumption among Saudi university students. Glob J Health Sci. 2014;6(2):155.

38. Azm SA, Elebiary HA. Prevalence of overweight and obesity in relation to life-style among Saudi Arabian female nursing students. Med J Cairo Univ. 2010;78(1):377-385.

39. Khalid U, Nosheen F, Raza MA, et al. A comparative study about the daily intake of fruits and vegetables among female students of two universities of Faisalabad. Pak J Nutr. 2011;10(7):684-689. doi:10.3923/pjn.2011.684.689

40. Keller S, Maddock JE, Hannöver W, Thyrian JR, Basler H-D. Multiple health risk behaviors in German first year university students. Prev Med. 2008;46(3):189-195. doi:10.1016/j.ypmed.2007. 09.008

41. Dodd LJ, Al-Nakeeb Y, Nevill A, Forshaw MJ. Lifestyle risk factors of students: a cluster analytical approach. Prev Med. 2010;51 (1):73-77. doi:10.1016/j.ypmed.2010.04.005

42. Chourdakis M, Tzellos T, Papazisis G, Toulis K, Kouvelas D. Eating habits, health attitudes and obesity indices among medical students in northern Greece. Appetite. 2010;55(3):722-725. doi:10.1016/j.appet. 2010.08.013
43. WHO Expert Consultation. Appropriate body-mass index for Asian populations and its implications for policy and intervention strategies. Lancet. 2004;363(9403):157-163. doi:10.1016/S0140-6736(03)152 68-3

44. Epuru S, Eideh A, Bayoud AA, Alshammari E. Fruit and vegetable consumption trends among the female university students in Saudi Arabia. Eur Sci J. 2014;10(12).

45. Hung H-C, Joshipura KJ, Jiang R, et al. Fruit and vegetable intake and risk of major chronic disease. J Natl Cancer Inst. 2004;96 (21):1577-1584. doi:10.1093/jnci/djh296

46. Rydell SA, Harnack LJ, Oakes JM, Story M, Jeffery RW, French SA. Why eat at fast-food restaurants: reported reasons among frequent consumers. J Am Diet Assoc. 2008;108(12):2066-2070. doi:10.1016/ j.jada.2008.09.008

47. Collison KS, Zaidi MZ, Subhani SN, Al-Rubeaan K, Shoukri M, AlMohanna FA. Sugar-sweetened carbonated beverage consumption correlates with BMI, waist circumference, and poor dietary choices in school children. BMC Public Health. 2010;10(1):234. doi:10.1186/ 1471-2458-10-234

48. Madanat HN, Brown RB, Hawks SR. The impact of body mass index and Western advertising and media on eating style, body image and nutrition transition among Jordanian women. Public Health Nutr. 2007;10(10):1039-1046. doi:10.1017/S136898000 7666713

49. Sabra AA, Taha AZ, Al-Sebiany AM, Al-Kurashi NY, Al-Zubier AG. Coronary heart disease risk factors: prevalence and behavior among male university students in Dammam City, Saudi Arabia. J Egypt Public Health Assoc. 2007;82(1-2):21-42.

50. Al-Gelban KS. Dietary habits and exercise practices among the students of a Saudi Teachers' Training College. Saudi Med J. 2008;29(5):754.

51. Elshurbjy AJ, Ellulu MS. Association between stress and dietary behaviors among university students: mini-review. Med Clin Arch. 2017;1. doi:10.15761/MCA

52. Qureshi SR, Abdelaal AM, Janjua ZA, et al. Irritable bowel syndrome: a global challenge among medical students. Cureus. 2016;8 (8).

53. Saeed AA, Bahnassy AA, Al-Hamdan NA, Almudhaibery FS, Alyahya AZ. Perceived stress and associated factors among medical students. J Family Community Med. 2016;23(3):166. doi:10.4103/ 2230-8229.189132

54. Gower B, Hand CE, Crooks ZK. The relationship between stress and eating in college-aged students. Undergrad Res J Hum Sci. 2008; 7:1-9.

55. Fabian C, Pagan I, Rios JL, et al. Dietary patterns and their association with sociodemographic characteristics and perceived academic stress of college students in Puerto Rico. P R Health Sci J. 2013;32(1).

56. Goswami B. Prevalence of stress and its association with body weight among the medical students of Jorhat Medical College and Hospital, Jorhat. Int J Sci Study. 2017;4(11):1-3.

57. Firth J. Levels and sources of stress in medical students. $\mathrm{Br}$ Med $J$ (Clin Res Ed). 1986;292(6529):1177-1180. doi:10.1136/ bmj.292.6529.1177

58. Saipanish R. Stress among medical students in a Thai medical school. Med Teach. 2003;25(5):502-506. doi:10.1080/014215903100013 6716

59. Sherina M, Rampal L, Kaneson N. Psychological stress among undergraduate medical students. Med $J$ Malaysia. 2004;59 (2):207-211.

60. El-Gilany A-H, Amr M, Hammad S. Perceived stress among male medical students in Egypt and Saudi Arabia: effect of sociodemographic factors. Ann Saudi Med. 2008;28(6):442-448. doi:10.5144/ 0256-4947.2008.442

61. Power JJ. Disordered eating patterns in university students and links with stress coping: a literature review and discussion. Adv Pract Nurs. 2016;1(108):10-4172. 
62. Ahmed F, Al-Radhwan L, Al-Azmi G, Al-Beajan M. Association between stress and dietary behaviours among undergraduate students in Kuwait: gender differences. J Nutr Health Sci. 2014;1(1):14-16.

63. Austin SB, Melly SJ, Sanchez BN, Patel A, Buka S, Gortmaker SL. Clustering of fast-food restaurants around schools: a novel application of spatial statistics to the study of food environments. $\mathrm{Am}$ J Public Health. 2005;95(9):1575-1581. doi:10.2105/AJPH.2004. 056341
64. Davy SR, Benes BA, Driskell JA. Sex differences in dieting trends, eating habits, and nutrition beliefs of a group of midwestern college students. J Am Diet Assoc. 2006;106(10):1673-1677. doi:10.1016/j. jada.2006.07.017

65. Wardle J, Haase AM, Steptoe A, Nillapun M, Jonwutiwes K, Bellisie F. Gender differences in food choice: the contribution of health beliefs and dieting. Ann Behav Med. 2004;27(2):107-116. doi:10.1207/s15324796abm2702_5

\section{Publish your work in this journal}

The International Journal of General Medicine is an international, peer-reviewed open-access journal that focuses on general and internal medicine, pathogenesis, epidemiology, diagnosis, monitoring and treatment protocols. The journal is characterized by the rapid reporting of reviews, original research and clinical studies

Submit your manuscript here: https://www.dovepress.com/international-journal-of-general-medicine-journal across all disease areas. The manuscript management system is completely online and includes a very quick and fair peer-review system, which is all easy to use. Visit http://www.dovepress.com/ testimonials.php to read real quotes from published authors. 